\title{
Multi-gram Preparation of 7-Nitroquinoxalin-2-amine
}

\author{
Daniel N. do Amaral, ${ }^{a, b, c}$ Fernando R. de Sá Alves, ${ }^{c}$ Eliezer J. Barreiro, ${ }^{a, b}$ \\ Stefan A. Laufer ${ }^{c}$ and Lídia M. Lima*,a,b \\ ${ }^{a}$ Laboratório de Avaliação e Síntese de Substâncias Bioativas (LASSBio), \\ Universidade Federal do Rio de Janeiro, C. P. 68024, 21944-971 Rio de Janeiro-RJ, Brazil \\ ${ }^{b}$ Programa de Pós-Graduação em Farmacologia e Química Medicinal, \\ Instituto de Ciências Biomédicas, Universidade Federal do Rio de Janeiro, \\ Avenida Carlos Chagas Filho, 373, Ilha do Fundão, 21941-912 Rio de Janeiro-RJ, Brazil \\ ${ }^{c}$ Department of Pharmaceutical/Medicinal Chemistry, \\ Institute of Pharmacy and Interfaculty Center for Pharmacogenomics and Drug Research (ICEPHA), \\ Eberhard-Karls-University Tübingen, Auf der Morgenstelle 8, 72076 Tübingen, Germany
}

\begin{abstract}
Methodologies to obtain quinoxaline compounds regioselectively are rarely reported in literature, thus regioselective and multi-gram methodologies to obtain these derivatives are desirable to explore the entire potential of these scaffolds for academic and/or commercial application. A facile and multi-gram methodology is described to obtain compound 7-nitroquinoxalin-2-amine using $o$-phenylenediamine, a cheap and readily available reactant, as starting material in a five-step procedure in good yields and high purity without further purification such as crystallization or column chromatography.
\end{abstract}

Keywords: quinoxaline, 7-nitroquinoxaline-2-amine, regioselective nitration

\section{Introduction}

Quinoxalines or benzopyrazines are heterocyclic compounds that present designed properties for commercial and/or academic applications as dyes, drugs or pharmacological tools. ${ }^{1,2}$ Methodologies to obtain quinoxaline compounds regioselectively are rarely reported in literature, thus regioselective and multi-gram methodologies to obtain those derivatives are desirable to explore the entire potential of these scaffolds.

It is worth mentioning that 7-nitroquinoxalin-2-amine is an interesting functionalized scaffold, which can easily be a substrate for chemoselective functional group interconversion, aiming the further synthesis of bioactive compounds, containing pharmacophore groups linked to the nitrogen-substituents of positions 2 and 7 of quinoxaline nucleus. The $N$-(2-(2-phenylureido) quinoxalin-7-yl) acrylamides, designed in order to contain the structural requirements to inhibit epidermal growth factor receptors, are examples of structural pattern that can be obtained from 7-nitroquinoxalin-2-amine scaffold.

*e-mail: lidia@lassbio.icb.ufrj.br
So far, synthesis of 7-nitroquinoxalin-2-amine was only described once in the literature by Wolf et al. ${ }^{3}$ in 1949. Wolf's methodology uses 4-nitro-o-phenylenediamine as starting material and it is not regioselective. Separation of regioisomers was done by crystallization from the mixture of aryl chlorides using ligroin and benzene as solvents. Regioisomers are described regarding their melting point (mp) as A (higher melting point) and B (lower melting point). Besides, characterization of regioisomers 6-nitroquinoxalin-2-amine and 7-nitroquinoxalin-2-amine was not done, as scales and yields were also not described.

\section{Results and Discussion}

Our procedure (Scheme 1) uses $o$-phenylenediamine as starting material to prepare initially quinoxalin-2-ol (2) in good yields and different scales (0.3-10.0 g) as described by Kobayashi et al. ${ }^{4}$ Next, 7-nitroquinoxalin-2-ol (3) was regioselectively obtained by a methodology using fuming nitric acid and glacial acetic acid at room temperature as described by Deng et al..$^{5}$ This step is scale sensitive, and attempts to increase or decrease scale $(0.5$ or $4.0 \mathrm{~g})$ were unsuccessful. Nitration of quinoxaline-2-ol scaffold was 
confirmed by DEPT-135 (distortionless enhancement by polarization) spectra and melting point. Chemical shifts from ${ }^{1} \mathrm{H}$ and ${ }^{13} \mathrm{C}$ nuclear magnetic resonance (NMR) spectra of the obtained isomer are in accordance with values previously described for the 7-nitroquinoxalin-2-ol. ${ }^{5}$ NOE (nuclear Overhauser effect) difference experiment also confirmed obtainment of regioisomer 3. By using phosphoryl chloride under refluxing conditions, we prepared the corresponding aryl chloride 2-chloro-7-nitroquinoxaline (4) in good yields by filtration after slowly addition of the reaction mixture into a mixture of ice and water. ${ }^{6}$

Although the amination of 2-chloroquinoxaline is described as easily done, we could not reproduce chlorine substitution by an amino group at 7-nitroquinoxaline scaffold as previously described in literature. ${ }^{3,7}$ Ammonia in methanolic solution at high temperatures, through nucleophilic aromatic substitution in similar procedure as described by Wolf et $a l^{3}{ }^{3}$ and by Gowenlock et al. ${ }^{7} \mathrm{did}$ not yield the desired product. Different methodologies were employed to prepare amidine compound such as: ammonium hydroxide with copper iodide under microwave irradiation, urotropine in ethanol under reflux, and Koródi reaction. ${ }^{8}$ However, none of these methodologies were effective.

Therefore, use of benzylamines was proposed to act as amino group carrier and then, in a second step, after a deprotection reaction, we could obtain the final compound. ${ }^{9}$ Considering the nitro group and atom economy green chemistry principle, $p$-methoxybenzylamine (PMBAM) was chosen as amino carrier group, once benzylamine moiety removal by hydrogenation with paladium over carbon would lack chemioselectivity, also reducing the nitro group, and considering that 3,5-dimethoxybenzylamine has more methoxy groups in its structure than PMBAM.

Firstly, compound 5 was obtained by a methodology using DMF (dimethylformamide) as solvent. ${ }^{10}$ This methodology uses higher amounts of amine and the removal of DMF was a time demanding issue. To circumvent these issues, a more environment friendly methodology was employed using 1.05 equivalent of amine and 3 equivalent of triethylamine in ethanol under refluxing conditions, ${ }^{11}$ see Table 1. Corresponding $p$-methoxybenzylamine derivative (5) was obtained after solvent removal and water washing by filtration in good yields ( $>90 \%$ ).

Amino group deprotection was done using TFA (trifluoroacetic acid) at $50^{\circ} \mathrm{C}$ for $24 \mathrm{~h}$ and final compound 6 was obtained in high yields and purity. ${ }^{12} 7$-Nitroquinoxalin2 -amine $(\mathbf{6})$ is an orange powder $\left(\mathrm{mp}>300^{\circ} \mathrm{C}\right)$, insoluble in common organic solvents as dichloromethane, chloroform, ethyl acetate, methanol, ethanol and acetonitrile.

\section{Conclusions}

In summary, we described a methodology that is affordable for academic and/or commercial purposes by a five-step synthetic pathway through common synthetic procedures. Intermediates and the final product were obtained by filtration from water and needed no further purification procedures to yield the compounds in multigram scales (up to $10 \mathrm{~g}$ of starting material). Chemical characterization $\left({ }^{1} \mathrm{H}\right.$ and ${ }^{13} \mathrm{C}$ NMR, ATR/FTIR (attenuated total reflection/Fourier Transform infrared secptroscopy) and MS (mass spectrometry)) and regioselective preparation of 7-nitroquinoxalin-2-amine are herein described for the first time.

\section{Experimental}

All commercially available reagents and solvents were used without further purification. ${ }^{1} \mathrm{H}$ and ${ }^{13} \mathrm{C}$ NMR and DEPT-135 spectra were determined in DMSO- $d_{6}$ or $\mathrm{D}_{2} \mathrm{O}$ solutions using a Bruker AC-200 or a Bruker Avance 400 spectrometer. The chemical shifts are given in parts per million (ppm) from solvent residual peaks<smiles>CC(C)(C)C1(C)CC1(C)C</smiles><smiles>COc1ccc(CNc2cnc3ccc([N+](=O)[O-])cc3n2)cc1</smiles>

Scheme 1. (a) Glyoxylic acid, methanol, $0{ }^{\circ} \mathrm{C}$-room temperature, $1 \mathrm{~h}(89 \%)$; (b) $\mathrm{HNO}_{3} /$ glacial $\mathrm{AcOH}$, room temperature, $24 \mathrm{~h}(65 \%)$; (c) $\mathrm{POCl} \mathrm{l}_{3}$, reflux, $3 \mathrm{~h}(96 \%)$; (d) p-methoxybenzylamine, triethylamine, ethanol, reflux, $3 \mathrm{~h}(93 \%)$, and (e) TFA (trifluoroacetic acid), $50{ }^{\circ} \mathrm{C}, 24 \mathrm{~h}(95 \%)$. 
Table 1. Optimization of nucleophilic aromatic substitution to prepare compound $\mathbf{5}$

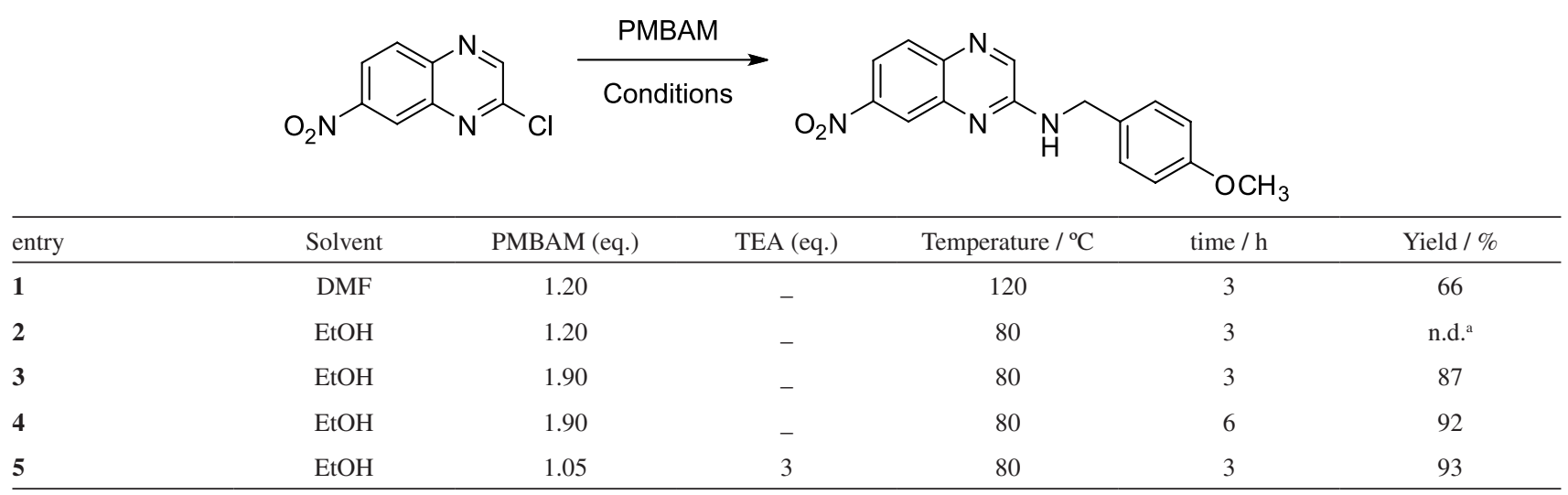

${ }^{a}$ Yield was not determined (n.d.) since the obtained product (5) was impure with reactant (4) after filtration. PMBAM: p-methoxybenzylamine; TEA: triethylamine; DMF: dimethylformamide.

and the coupling constant values $(J)$ are given in $\mathrm{Hz}$. Signal multiplicities are represented by: s (singlet), $\mathrm{d}$ (doublet), dd (double doublet), $\mathrm{t}$ (triplet), $\mathrm{m}$ (multiplet) and br (broad signal). FTIR spectra were obtained using a Thermo Scientific Nicolet's Avatar iS10 spectrometer equipped with smart endurance diamond ATR unit for direct measurements. Mass spectra were obtained from a TLC-MS (thin layer chromatography) interface CAMAG in negative mode and from a Hewlette Packard HP 5973 mass selective detector $(70 \mathrm{eV})$. Melting points were determined using a MP70 Mettler Toledo and are uncorrected. The purity of compounds was determined by high-performance liquid chromatography (HPLC, Merck Hitachi L-6200 intelligent pump, Merck Hitachi AS-2000 auto sampler, Merck Hitachi L-4250 UV-Vis detector) using a Zorbax ${ }^{\circledR}$ Eclipse XDB C8 column (5 mm), employing a gradient of $0.01 \mathrm{M} \mathrm{KH}_{2} \mathrm{PO}_{4}$ $(\mathrm{pH} 2.3)$ and methanol as solvent system with a flow rate of $1.5 \mathrm{~mL} \mathrm{~min}^{-1}$ and detection at 230 and $254 \mathrm{~nm}$.

Procedure for the synthesis of quinoxalin-2-ol (2)

A solution of $o$-phenylenediamine $(\mathbf{1})(10.0 \mathrm{~g}, 93 \mathrm{mmol})$ in methanol $(100 \mathrm{~mL})$ was slowly added to an ice bath cooled solution of glycoxilic acid monohydrate $(10.2 \mathrm{~g}$, $111 \mathrm{mmol})$ in methanol $(120 \mathrm{~mL})$ and the mixture was kept at room temperature for $1 \mathrm{~h}$ after addition of the $o$-phenylenediamine solution. $12.0 \mathrm{~g}$ of a white crystalline solid were obtained after filtration and washing with water. Yield 89\%; mp 269-270 ${ }^{\circ} \mathrm{C}$ (lit. 268-270 ${ }^{\circ} \mathrm{C}$ ) $;^{4}$ ATR/FTIR $\mathrm{v} / \mathrm{cm}^{-1} 3302,1682,1638,898,753 ;{ }^{1} \mathrm{H}$ NMR $(200 \mathrm{MHz}$, DMSO- $\left.d_{6}\right) \delta 12.4(\mathrm{~s}, 1 \mathrm{H}, \mathrm{NH}), 8.16(\mathrm{~s}, 1 \mathrm{H}, \mathrm{H} 3), 7.76(\mathrm{~d}$, $1 \mathrm{H}, J$ 8.0, H8), 7.53 (t, 1H, J 8.0, H6), 7.26 (m, 2H, H5 and $\mathrm{H} 7) ;{ }^{13} \mathrm{C}$ NMR (50 MHz, DMSO- $\left.d_{6}\right) \delta 154.9,151.6$, $132.0,131.8,130.7,128.8,123.2,115.7$; DEPT-135 $\left(50 \mathrm{MHz}, \mathrm{DMSO}-d_{6}\right) \delta 151.6,130.7,128.8,123.2,115.7$; ESI-MS 145.0.

Procedure for the synthesis of 7-nitroquinoxalin-2-ol (3)

In a round bottom flask, $2.93 \mathrm{~g}(20 \mathrm{mmol})$ of quinoxalin2-ol (2) were stirred in $85 \mathrm{~mL}$ of glacial acetic acid at room temperature. Then, a solution of fuming nitric acid $(0.9 \mathrm{~mL})$ in glacial acetic acid $(5 \mathrm{~mL})$ was slowly added to the initial suspension. The mixture was stirred at room temperature for $24 \mathrm{~h}$ and after that, the solvent was evaporated and the residue was stirred for $1 \mathrm{~h}$ in $85 \mathrm{~mL}$ of water at room temperature before filtration and washing with water to give 7-nitroquinoxalin-2-ol (3) as a pale yellow solid $(2.51 \mathrm{~g})$. Yield $65 \%$; mp $273-274{ }^{\circ} \mathrm{C}$ (lit. $\left.273-276{ }^{\circ} \mathrm{C}\right),{ }^{5}$ ATR/FTIR v / $\mathrm{cm}^{-1} 1667,1620,1518,1347,898,752$; ${ }^{1} \mathrm{H}$ NMR $\left(200 \mathrm{MHz}, \mathrm{DMSO}-d_{6}\right) \delta 12.73$ (s, $\left.1 \mathrm{H}, \mathrm{NH}\right), 8.36$ (s, 1H, H3), 8.10 (d, 1H, J 2.0, H8), 8.04 (dd, 2H, H5 and H6); ${ }^{13} \mathrm{C}$ NMR (50 MHz, DMSO- $\left.d_{6}\right) \delta 155.4,154.5,147.6$, 135.3, 132.3, 130.2, 117.4, 111.2; DEPT-135 (50 MHz, DMSO- $\left.d_{6}\right) \delta 155.4,130.2,117.4,111.2$; ESI-MS 190.0.

Procedure for the synthesis of 2-chloro-7-nitroquinoxaline (4)

In a round bottom flask, a mixture of 7-nitroquinoxalin2-ol (3) (12.73 g, $67 \mathrm{mmol}$ ) in $20 \mathrm{~mL}$ of phosphoryl chloride $\left(\mathrm{POCl}_{3}\right)$ was refluxed for $3 \mathrm{~h}$. Then, the mixture was slowly poured into a stirred mixture of ice and water. The precipitate was filtrated and washed with water to obtain $13.43 \mathrm{~g}$ of a red/cherry solid. Yield $96 \%$; mp $183-186{ }^{\circ} \mathrm{C}$ (lit. $185-189^{\circ} \mathrm{C}$ ); ${ }^{5}$ ATR/FTIR v / $\mathrm{cm}^{-1} 3092,3048,1682$, $1525,1350,740 ;{ }^{1} \mathrm{H}$ NMR (200 MHz, DMSO- $\left.d_{6}\right) \delta 9.22$ (s, 1H, H3), 8.88 (d, 1H, J 3.0, H8), 8.59 (dd, 1H, J 2.0, 
9.0, H6), 8.39 (d, 1H, J 9.0, H5); ${ }^{13} \mathrm{C}$ NMR (100 MHz, DMSO- $\left.d_{6}\right) \delta 149.2,148.8,148.3,142.8,140.2,130.9$, 124.1, 123.9; DEPT-135 (100 MHz, DMSO- $\left.d_{6}\right) \delta 148.8$, 130.9, 124.1, 123.9; MS 209.1 + 211.1.

Procedure for the synthesis of $\mathrm{N}$-(4-methoxybenzyl)7-nitroquinoxalin-2-amine (5)

$20 \mathrm{~mL}$ of triethylamine (3 eq.) and $6.8 \mathrm{~mL}$ of $p$-methoxybenzylamine (1.05 eq.) were added to a solution of 2-chloro-7-nitroquinoxaline (4) (10.13 g, $48 \mathrm{mmol})$ in ethanol $(160 \mathrm{~mL})$. The reaction mixture was refluxed for $3 \mathrm{~h}$. The solution was evaporated and the solids were filtered and washed with water to obtain an orange colored solid (13.94 g). Yield 93\%; mp 171-173 ${ }^{\circ} \mathrm{C}$ (lit. 167-169 $\left.{ }^{\circ} \mathrm{C}\right) ;{ }^{13}$ ATR/FTIR $v / \mathrm{cm}^{-1} 3389,3077,2928,1615,1538,1509$, 1338,$741 ;{ }^{1} \mathrm{H}$ NMR $\left(200 \mathrm{MHz}\right.$, DMSO- $\left.d_{6}\right) \delta 8.50(\mathrm{t}, 2 \mathrm{H}$, $J$ 6.0, NH and H3), 8.27 (d, 1H, J 2.0, H8), 8.05 (dd, $1 \mathrm{H}$, $J$ 2.0, 9.0, H6), 7.96 (d, 1H, J 8.0, H5), 7.36 (d, 2H, J 8.0, H3'), 6.91 (d, 2H, $J$ 8.0, H4'), 4.56 (d, 2H, $J$ 6.0, CH2), $3.73(\mathrm{~s}, 3 \mathrm{H}, \mathrm{OCH} 3) .{ }^{13} \mathrm{C}$ NMR (50 MHz, DMSO- $\left.d_{6}\right)$ $\delta 158.4,152.8,147.5,143.6,141.4,139.3,130.4,129.9$, 129.2, 120.9, 116.8, 113.8, 55.1, 43.3; DEPT-135 (50 MHz, DMSO- $\left.d_{6}\right) \delta 143.6,129.9,129.2,120.9,116.8,113.8$, 55.1, 43.3; ESI-MS 309.3; HPLC at $230 \mathrm{~nm} 96.7 \%$ and at $254 \mathrm{~nm} 100 \%$.

Procedure for the synthesis of 7-nitroquinoxalin-2-amine (6)

$\mathrm{N}$-(4-Methoxybenzyl)-7-nitroquinoxalin-2-amine (5) (13.9 g, $45 \mathrm{mmol}$ ) was added to a round bottom flask containing trifluoroacetic acid $(85 \mathrm{~mL})$. The mixture was heated at $50^{\circ} \mathrm{C}$ for $24 \mathrm{~h}$. Trifluoroacetic acid was evaporated and brine was added to the flask and a dark brown solid was obtained after filtration. This solid was washed with ethyl acetate and filtrated to furnish an orange solid with high purity $(8.15 \mathrm{~g})$. Yield $95 \%$; $\mathrm{mp}>300^{\circ} \mathrm{C}$; ATR/FTIR $v / \mathrm{cm}^{-1} 3428,3324,3116,1660,1566,1522,1348,741$. ${ }^{1} \mathrm{H}$ NMR (200 MHz, DMSO- $d_{6}$ ) $\delta 8.45$ (s, 1H, H3), 8.22 (d, 1H, J 2.0, H8), 8.05 (dd, 1H, J 2.0, 9.0, H6), 7.96 (d, $1 \mathrm{H}, J$ 9.0, H5), 7.49 (br, exchange with $\mathrm{D}_{2} \mathrm{O}, 2 \mathrm{H}, \mathrm{NH}_{2}$ ). ${ }^{13} \mathrm{C}$ NMR (50 MHz, DMSO- $\left.d_{6}\right) \delta 154.5,147.7,143.0$, 141.6, 139.2, 130.1, 120.7, 116.8; DEPT-135 (50 MHz, DMSO- $\left.d_{6}\right) \delta 143.0,130.1,120.7,116.8$; ESI-MS 189.1; HPLC at $230 \mathrm{~nm} 98.5 \%$ and at $254 \mathrm{~nm} \mathrm{100 \% .}$

\section{Supplementary Information}

Supplementary information $\left({ }^{1} \mathrm{H}\right.$ and ${ }^{13} \mathrm{C}$ NMR, DEPT-135, FTIR spectra and TLC-MS data) is available free of charge at http://jbcs.sbq.org.br as PDF file.

\section{Acknowledgments}

The authors would like to thank INCT-INOFAR (BR, 573.564/2008-6 and E-26/170.020/2008), CAPES/PSDE (BEX 4188/14-4), ICEPHA-Grants, DFG LA 1453/2-1 and Prof Arthur E. Kümmerle (ICE-DQ-UFRRJ) and staff by the NOE-dif experiment.

\section{References}

1. Sherif, S.; Ekladious, L.; Abdelmalek, G.; Adv. Synth. Catal. 1970, 312, 759; Pei, K.; Wu, Y.; Isklam, A.; Zhu, S.; Han, L.; Geng, Z.; Zhu, W.; J. Phys. Chem. C 2014, 118, 16552; Jung, C. Y.; Song, C. J.; Yao, W.; Park, J. M.; Hyun, I. H.; Seong, D. H.; Jaung, J. Y.; Dyes Pigm. 2015, 121, 204.

2. Gonzáles, M.; Cerecetto, H.; Expert Opin. Ther. Pat. 2012, 11, 1289; Gobec, S.; Urleb, U. In Science of Synthesis, Houben-Weyl Methods of Molecular Transformations, category 2, vol. 16; Yamamoto, Y., ed.; Georg Thieme Verlag- Stuttgart: New York, USA, 2004, p. 845.

3. Wolf, F. J.; Pfister, K.; Beutel, R. H.; Wilson, R. M.; Robinson, C. A.; Stevens, J. R.; J. Am. Chem. Soc. 1949, 71, 6.

4. Kobayashi, H.; Maruyama, H.; Shuji, K.; Sodahiko, N.; European pat. EP0444619A2, 1991.

5. Deng, J.; Feng, E.; Ma, S.; Zhang, Y.; Liu, X.; Li, H.; Huang, H.; Zhu, J.; Zhu, W.; Shen, X.; Miao, L.; Liu, H.; Jiang, H.; Li, J.; J. Med. Chem. 2011, 54, 4508.

6. Hazeldine, S. T.; Polin, L.; Kushner, J.; Paluch, J.; White, K.; Edelstein, M.; Palomino, E.; Corbett, T. H.; Horwitz, J. P.; J. Med. Chem. 2001, 44, 1758.

7. Gobec, S.; Urleb, U. In Science of Synthesis, Houben-Weyl Methods of Molecular Transformations, category 2, vol. 16; Yamamoto, Y., ed.; Georg Thieme Verlag- Stuttgart: New York, USA, 2004, p. 891; Gowenlock, A. H.; Newbold, G. T.; Spring, F. G.; J. Chem. Soc. 1945, 622.

8. Doherty, E. M.; Fotsch, C.; Bannon, A. W.; Bo, Y.; Chen, N.; Dominguez, C.; Falsey, J.; Gavva, N. R.; Katon, J.; Nixey, T.; Ognyanov, V. I.; Pettus, L.; Rzasa, R. M.; Stec, M.; Surapaneni, S.; Tamir, R.; Zhu, J.; Treanor, J. J. S.; Norman, M. H.; J. Med. Chem. 2007, 50, 3515; Blazevic, N.; Kolbah, D.; Synthesis 1979, 3, 161; Inglis, S.; Jones, R.; Fritz, D.; Stojkoski, C.; Booker, G.; Pyke, S.; Org. Biomol. Chem 2005, 3, 2543.

9. Pelcman, B.; Sanin, A.; Nilsson, P.; Kromann, H.; PCT Int. Appl. WO 2007051982, 2007; Cook II, J. H.; Mcdonald, I. M.; Dalton, K.; Olson, R. E.; Wang, N.; Iwuagwu, C. I.; Zusi, C. F.; Macor, J. E.; PCT Int. Appl. WO 2011053292, 2011.

10. Venkatesh, C.; Singh, B.; Mahata, P. K.; Ila, H.; Junjappa, H.; Org. Lett. 2005, 27, 2169.

11. Gabler, M.; Schubert-Zsilavecz, M.; Molecules 2011, 16, 10013.

12. Fox, B. M.; Sugimoto, K.; Lio, K.; Yoshida, A.; Zhang, J.; Li, K.; Hao, X.; Labelle, M.; Smith, M.; Rubenstein, S. M.; Ye, G.; 
McMinn, D.; Jackson, S.; Choi, R.; Shan, B.; Ma, J.; Miao, S.; Matsui, T.; Ogawa N.; Suzuki, M.; Kobayashi, A.; Ozeki, H.; Okuma, C.; Ishii, Y.; Tomimoto, D.; Furakawa, N.; Tanaka, M.; Matsushita, M.; Takahashi, M.; Inaba, T.; Sagawa, S.; Kayser, F.; J. Med. Chem. 2014, 57, 3464.
13. Loriga, M.; Fiore, M.; Sanna, P.; Paglietti, G.; Il Farmaco 1996, $51,559$.

Submitted: July 14, 2016

Published online: February 6, 2017 